\title{
A perception of medical students about role of cinema on mental health
}

\section{Huma Khan ${ }^{1}$, Abhinav Pandey ${ }^{2}$, Vertika Agarwal ${ }^{3}$, Saurabh Mishra ${ }^{4}$}

${ }^{1}$ Associate Professor, Department of Community Medicine, Shri Ram Murti Smarak Institute of Medical Sciences, Bareilly, Uttar Pradesh; ${ }^{2}$ Assistant Professor, Department of Community Medicine, Shri Ram Murti Smarak Institute of Medical Sciences, Bareilly, Uttar Pradesh; ${ }^{3}$ Tutor, Department of Community Medicine, Shri Ram Murti Smarak Institute of Medical Sciences, Bareilly, Uttar Pradesh; ${ }^{4}$ Statistician (Independent) R/O -172, Mohalla Baradari, Shahjahanpur, Uttar Pradesh

\begin{tabular}{|c|c|c|c|c|c|c|c|c|}
\hline Abstract & Introduction & Methodology & Results & Conclusion & References & Citation & \multicolumn{2}{|c|}{ Tables / Figures } \\
\hline \multicolumn{9}{|c|}{ Corresponding Author } \\
\hline \multicolumn{8}{|c|}{$\begin{array}{l}\text { Dr Huma Khan, Associate Professor, Community Medicine, Shri Ram Murti Smarak Institute of Medical } \\
\text { Sciences, Bareilly, Uttara Pradesh- } 243202 \\
\text { E Mail ID: humakgupta@gmail.com }\end{array}$} & 回评回 \\
\hline
\end{tabular}

\section{Citation}

Khan H, Pandey A, Agarwal V, Mishra S. A perception of medical students about role of cinema on mental health. Indian J Comm Health. 2021;33(2):364-367. https://doi.org/10.47203/IJCH.2021.v33i02.024

Source of Funding: Nil Conflict of Interest: None declared

\section{Article Cycle}

Received: 14/04/2021; Revision: 03/06/2021; Accepted: 13/06/2021; Published: 30/06/2021

This work is licensed under a Creative Commons Attribution 4.0 International License.

\section{Abstract}

Background: Among few of the recreational activities of students are sports and watching cinema. Movies are found to be powerful instruments in influencing the attitudinal changes, emotional impact, education, life styles, health and other behaviours. Objectives 1 . Choice of cinema among medical students 2. Perceived effects of watching cinema on study participants. Methods- This was a cross sectional study carried out among undergraduate medical students. Sample size: 153. Result: Age of the participants ranged from 18-29 years averaging 21.43 years. Bollywood movies were the most commonly watched by 113 (73.9\%) followed by Hollywood movies watched by 104 (68\%) study participants.77 (50.3\%) participants believed that movies showing sexual violence against females badly affect the psyche of females.

\section{Keywords}

Cinema; Mental Health; Students

\section{Introduction}

Among the many recreational activities of students are sports and watching cinema. Cinema can create not only temporary phenomenal experiences but also change the cultural climate. Movies are found to be powerful instruments in influencing the attitudinal changes, emotional impact, education, life styles, health and other behaviours. (1) Movies happen to be the most influential tool of communication and society happens to learn a lot of things from films $(2,3)$. One's passion for films can shape the way he thinks, behaves and feel within a society(4). Changing our rituals, behaviour, outlook towards life is somehow connected with what we see on screen.(5) Cinema possesses a power and also offers an unrivalled medium for entertainment and escapism. Film is a form of entertainment that has the power to alter the beliefs of people seemingly every possibly way.(6) Cinema can tell motivational stories on one hand but on the other hand it can also puts violence and negative stories too. Fictional television and film violence contribute to an increase in aggression and violence(7)

Current study with following objectives will try to look into the effects of cinema on mental health of medical students and other factors behind those effects.

\section{Aims \& Objectives}

1. Choice of cinema among medical students

2. Perceived effects of watching cinema on study participants

\section{Material \& Methods}

Study Type: This was a descriptive, cross sectional study. Study Population: The study was carried out among undergraduate medical students. Study Area: A private medical college in Western part of Uttar Pradesh. Study Duration: The study was conducted during 1 February 2020 to 14 March 2020. Sample Size calculation: Convenient sampling method was used to select the study participants. Data was collected from 153 study participants. Inclusion Criteria: MBBS students more than 18 years of age giving voluntary verbal consent to 
participate in the study. Exclusion criteria: (1). MBBS students younger than 18 years of age. (2). MBBS students who did not give consent to participate in the study.

Strategy for collection: All the MBBS students were informed about the study in their respective classes and students who volunteered to participate in the study were provided the questionnaire in printed form in a sealed envelope. They were asked to fill the questionnaire at their privacy and convenience and to return it back within one week in sealed envelope. No identifying information was collected and complete anonymity was maintained. They were instructed to put that sealed envelope in a cardboard box kept in a common area for this purpose. A total of 153 students returned back the questionnaires marked with responses.

Ethical Approval: Study was started only after getting the Ethical Clearance certificate from the Institute's Ethics Committee. Consent: Verbal informed consent was taken. Data Analysis: Data were entered in Microsoft Excel 2007 and was analyzed in SPSS trial version.

\section{Results}

Age of the participants ranged from $18-29$ years averaging 21.43 years with a standard deviation of \pm 1.44 years.

Type of cinema: Bollywood movies were the most commonly watched by 113 (73.9\%) followed by Hollywood movies watched by 104 (68\%) study participants. Chinese movies were the least watched cinema watched by only 12 (7.8\%) participants.

Genre of cinema: Murder mysteries were most watched by $106(69.28 \%)$, followed by Science fiction watched by 97 (63.4\%). Porn movies were least watched by 15 (9.8\%). Frequency of watching cinema: Out of 153 participants ,49 (32\%) reported to watch a movie once a month in a theatre whereas 39 (25.5\%) reported to watch a movie 23 times a month by streaming through internet and 28 (18.3\%) participants reported to watch a movie 2-3 times a month through paid movie subscriptions.

\section{Socio demographic factors:}

Gender: Male gender was found to be associated more with watching Hollywood movies $(p=0.008)$, Action movies $(p=0.000)$, War movies $(p=0.000)$, Porn movies $(p=0.002)$ and monthly expenses more than 500/- per month in comparison to females $(p=0.032)$. (Table 1)

Religion: Participants belonging to Muslim religion ware found to watch action movies in comparison to Hindus $(p=0.049)$, Participants belonging to Hindu religion were found to watch Love stories in comparison to Muslims $(p=0.039)$. Participants whose fathers were businessmen were less likely to watch Hollywood movies than those whose fathers were businessmen $(p=0.016)$.

Native Place: Participants whose native place was urban area were more likely to watch murder mysteries than their rural counterparts $(p=0.008)$. Participants belonging to joint families were more likely to watch documentaries in comparison to their counterparts who belonged to nuclear families $(p=0.010)$

Perceived effects of watching cinema on medical students: 77 (50.3\%) participants believed that movies showing sexual violence against females badly affect the psyche of females. Whereas 65 (42.5\%) participants believed that movies showing sexual violence against females badly affect the psyche of males.

Study participants reported to like the most of the times the Dressing (42.5\%), Mannerism (30.7\%), Looks (33.3\%) and Language $(25.5 \%)$ of an actor or actress. $71 \%$ of study participants reported to rarely like drinking by male or female actors in the movies.

Majority of the participants (>75\%) rarely like Smoking by males or female, mocking or teasing by males or females, forcing others to do undesired acts, Physical Violence, threatening others with a knife or a gun by males or female, actors in movies.

114 (74.5\%) believed that women who view a lot of sexual violence in movies may become fearful. 94 (61.4\%) participants also believed that women who view a lot of sexual violence may develop low self-esteem.(Figure 2), (Figure 3)

On the other hand 113 (73.9\%) participants believed that movies showing sexual violence against females, educates society against it. (Table 2) \& (Figure 4)

$103(67.3 \%)$ reported that movies showing sexual violence against females makes them fearful and 107 (69.9\%) participants reported that movies showing physical violence makes them feel aggressive.(Figure 5)

\section{Discussion}

77 (50.3\%) and 65 (42.5\%) participants believed that movies showing sexual violence against females badly affect the psyche of females and males respectively In the study conducted by Istiak Mahmood (5), 90\% participants reported that increasing of violence, sexual assault, direct connection with movies.

In present study, murder mysteries were most watched by 106 (69.28\%), followed by Science fiction watched by 97 (63.4\%). Porn movies were least watched by 15 (9.8\%). Hassan et al (8) reported that $78 \%$ of respondent selected "action" movies as first choose. "Animation" was second with $41.2 \%$ and "comedy" was third with $39.8 \%$.

In our study porn movies were watched by $9.8 \%$. Whereas Michelle S (9) reported that $80.3 \%$ participants watch online pornography.

\section{Conclusion}

Cinema is a powerful medium to bring about changes in individual and society too. It can make us fearful and it can educate us too. Families and individuals must pay great care on what they are watching.

\section{Recommendation}

We should have stricter censorship control on the content of cinema. 


\section{Limitation of the study}

A qualitative study on this subject would have yielded a more specific information. A larger sample size including students from different streams could have given a better perception on this topic.

\section{Relevance of the study}

Role of Cinema in mental and emotional health of the viewers has been explored very little. This study tried to fill this gap.

\section{Authors Contribution}

HK has conceptualized the idea, AP helped in data collection, VA helped in writing the paper in present form and SM contributed in data analysis as an independent statistician.

\section{Acknowledgement}

We acknowledge the contribution of the study participants who shared their views in an uninhibited manner.

\section{References}

1. Persson $\mathrm{P}$, Understanding cinema : A psychological theory of moving imagery. Cambridge University Press 2003; https://pdfs.semanticscholar.org
Ghosal A. Impact of Indian sports movies on sports culture of India. International Journal of Physiology, Nutrition and Physical Education. 218;3(2):507-511.

3. Itoo MK, Nagar K. Impact of a negative portrayal of a destination in Bollywood movies on viewers' attitude towards the destination, intention to visit and destination image. Pacific Business Review International, 2017;10(5):71-82.

4. Jain A. Lata P, Goyal AR, Khandelwal S, Jain G. Sociocultural impact of film celebrities on teenagers: An empirical study. International Journal of Indian Culture and Business Management, 2015;11(3):308-322.

5. Istiak M, Influence and Importance of Cinema on the Lifestyle of Educated Youth: A study on University Students of Bangladesh. IOSR Journal Of Humanities And Social Science. 2013;17(6): 77-80.

6. Anand P, Srudin J, Rashmi J Menon, Branding in Movies and its Influence on Buying Behaviour, International Journal of Innovative Technology and Exploring Engineering (IJITEE). 2019;8(7S2)

7. Rowell Huesmann and Laramie D. Taylor, The role of media violence in violent behaviour. Annual Review of Public Health 2006 27(1):393-415.

8. Hassan, Salleh M. Effects of Watching Violence Movies on the Attitudes Concerning Aggression among Middle Schoolboys (13-17 years old) at International Schools in Kuala. European Journal of Scientific Research 2009;38(1):141-156

9. Michelle S. Online pornography and its effects on the behavior of college students, https://digital.library.unt.edu/ark . (Accessed on 25.06.2021)

\section{Tables}

\section{TABLE 1 SOCIO-DEMOGRAPHIC CHARACTERISTICS OF THE STUDY PARTICIPANTS}

\begin{tabular}{|c|c|c|}
\hline Socio-Demographic characteristics & No. & Percentage \\
\hline \multicolumn{3}{|l|}{ Gender } \\
\hline Male & 64 & 41.83 \\
\hline Female & 89 & 58.17 \\
\hline Age Group & & 0.00 \\
\hline $18-21$ & 79 & 51.63 \\
\hline 22-29 & 74 & 48.37 \\
\hline \multicolumn{3}{|l|}{ Type of family } \\
\hline Nuclear & 136 & 88.89 \\
\hline Joint & 33 & 21.57 \\
\hline Occupation of Father & & 0.00 \\
\hline Businessman & 66 & 43.14 \\
\hline Other & 87 & 56.86 \\
\hline Occupation of Mother & & 0.00 \\
\hline Housewife & 112 & 73.20 \\
\hline Working & 41 & 26.80 \\
\hline \multirow[t]{3}{*}{ Native Place } & & 0.00 \\
\hline & 136 & 88.89 \\
\hline & 17 & 11.11 \\
\hline
\end{tabular}

\section{TABLE 2 ASSOCIATION BETWEEN SOCIO DEMOGRAPHIC FACTORS AND CHOICE OF CINEMA}

\begin{tabular}{|c|c|c|c|c|}
\hline choice of cinema & preference to watch & Male & Female & \\
\hline \multirow[t]{2}{*}{ Bollywood } & Don't watch & $18(28.1 \%)$ & $22(24.7 \%)$ & \multirow[t]{2}{*}{$x^{2}=0.224, D f=1$} \\
\hline & Watch & $46(71.9 \%)$ & $67(75.3 \%)$ & \\
\hline \multirow[t]{2}{*}{ Hollywood } & Don't watch & $13(20.3 \%)$ & $36(40.4 \%)$ & \multirow[t]{2}{*}{$x_{2}=6.935, d f=1, p=0.008$} \\
\hline & Watch & $51(79.7 \%)$ & $53(59.6 \%)$ & \\
\hline \multirow[t]{2}{*}{ Action movies } & Don't watch & $16(25.0 \%)$ & $51(57.3 \%)$ & \multirow[t]{2}{*}{$x_{2}=15.783, d f=1, p=0.000$} \\
\hline & Watch & $48(75.0 \%)$ & $38(42.7 \%)$ & \\
\hline
\end{tabular}




\section{Figures}

\section{FIGURE 1 FLOW DIAGRAM}

Study Proposal submitted to the Institute Ethics Committee on 01/01/2020

Etical clearance certificate issued on 25/01/2020 ( SRMSIMS/IEC 2019-20/109

MBBS students were informed about the study in their respective classes during 01/02/2020 to 07/02/2020 and printed questionnaire were distributed

\section{Filled questionnaire were collected from the drop box kept in a common area on 14/02/2020}

\section{Data were entered in MS Exel 2007 and analysed in SPSS trial version during 14/02/2020 to 14/03/2020} FIGURE 2 EFFECT OF PHYSICAL VIOLENCE,
DEPICTED IN MOVIES ON SOCIETY

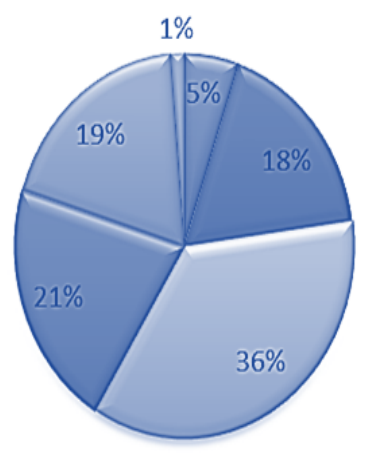

๑Strongly agree

口Agree

$\square$ Somewhat agree

घDisagree

$\square$ Strongly disagree

$\square$ Didn't answer
FIGURE 4 EFFECT OF SEXUAL VIOLENCE AGAINST FEMALES, DEPICTED IN MOVIES ON EMOTIONAL STATE

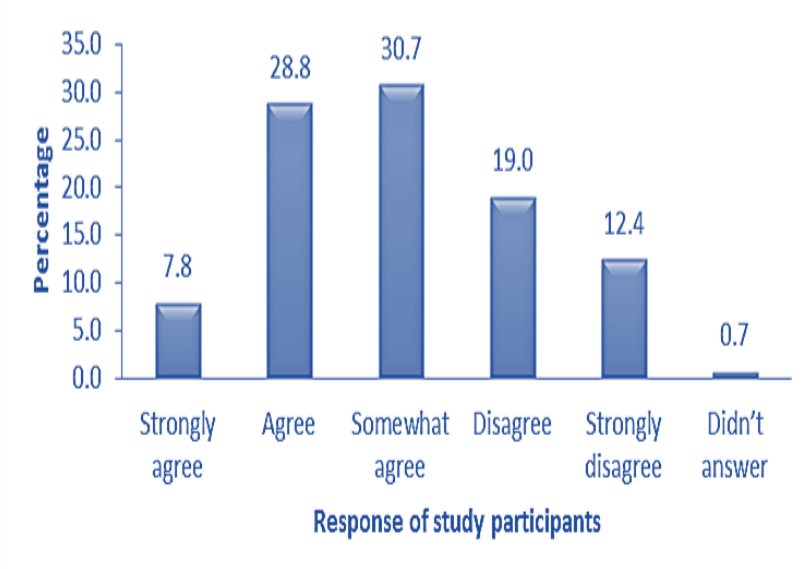

FIGURE 5 PERCEPTION ABOUT THE EFFECTS OF MOVIES ON EMOTIONAL STATE

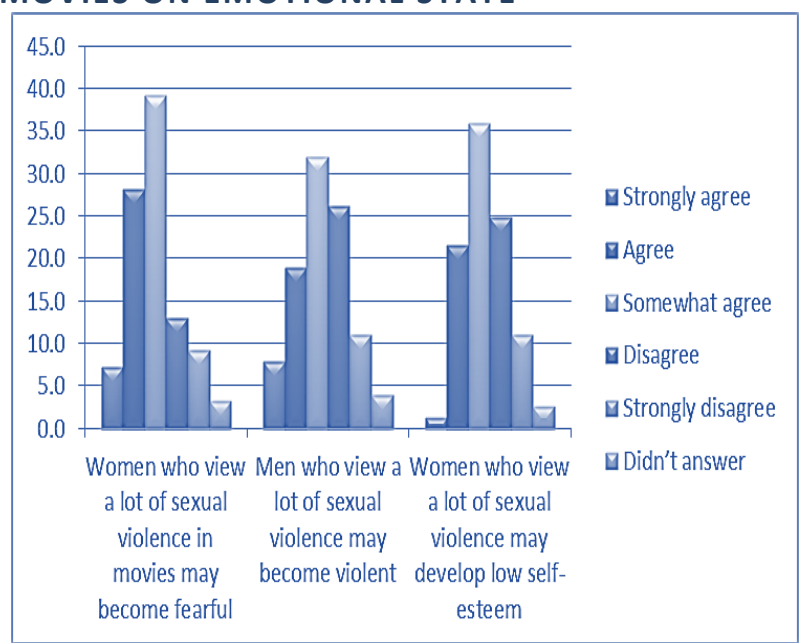

